\title{
Resistance in Tomato and Wild Relatives to Crown and Root Rot Caused by Phytophthora capsici
}

\author{
L. M. Quesada-Ocampo and M. K. Hausbeck
}

Department of Plant Pathology, Michigan State University, East Lansing 48824.

Accepted for publication 7 March 2010.

\begin{abstract}
Quesada-Ocampo, L. M., and Hausbeck, M. K. 2010. Resistance in tomato and wild relatives to crown and root rot caused by Phytophthora capsici. Phytopathology 100:619-627.

Phytophthora capsici causes root, crown, and fruit rot of tomato, a major vegetable crop grown worldwide. The objective of this study was to screen tomato cultivars and wild relatives of tomato for resistance to $P$. capsici. Four $P$. capsici isolates were individually used to inoculate 6-week-old seedlings ( $1 \mathrm{~g}$ of $P$. capsici-infested millet seed per $10 \mathrm{~g}$ of soilless medium) of 42 tomato cultivars and wild relatives of tomato in a greenhouse. Plants were evaluated daily for wilting and death. All $P$. capsici isolates tested caused disease in seedlings but some isolates were more pathogenic than others. A wild relative of cultivated tomato,

isolates tested. Moderate resistance to all isolates was identified in the host genotypes Ha7998, Fla7600, Jolly Elf, and Talladega. P. capsici was frequently recovered from root and crown tissue of symptomatic inoculated seedlings but not from leaf tissue or asymptomatic or control plants. The phenotype of the recovered isolate matched the phenotype of the inoculum. Pathogen presence was confirmed in resistant and moderately resistant tomato genotypes by species-specific polymerase chain reaction of DNA from infected crown and root tissue. Amplified fragment length polymorphisms of tomato genotypes showed a lack of correlation between genetic clusters and susceptibility to $P$. capsici, indicating that resistance is distributed in several tomato lineages. The results of this study create a baseline for future development of tomato cultivars resistant to $P$. capsici.
\end{abstract} Solanum habrochaites accession LA407, was resistant to all P. capsici
Tomato (Solanum lycopersicon L.) is a major vegetable crop grown worldwide. Each year, 160,000 to 280,000 ha of processing and fresh market tomato crops are planted in the United States, with an approximate value of $\$ 2$ billion (2). Phytophthora capsici Leonian is a destructive soilborne pathogen with a broad host range that includes solanaceous, cucurbitaceous, and fabaceous crops (9). On tomato, the pathogen causes root, crown, and fruit rot $(28,54)$, all of which have been reported in several regions, including Michigan (18), California (4,8,54), Colorado (28), and Florida (52).

In Michigan, tomato fruit are grown for fresh market and processing. Fresh-market production utilizes plastic-covered raised beds, trickle irrigation, and trellising to hold the plants upright; these management practices also limit disease caused by P. capsici (M. K. Hausbeck, unpublished data). Fresh-market tomato fruit are harvested by hand and have a higher profit margin than processing tomato fruit. Because processing tomato fruit are mechanically harvested and have a lower profit margin, plants are grown on flat ground where fruit typically come into direct contact with the soil. The growing system used by processing-tomato growers is more conducive to $P$. capsici infection than the fresh-market system. In Michigan, crop rotation and fungicide applications are commonly used to manage $P$. capsici. The success of crop rotation is limited by the long-term survival of oospores in the soil (32) and the number and diversity of susceptible hosts $(15,45)$. Applications of the commonly used fungicide mefenoxam may not protect susceptible crops from resistant $P$. capsici populations, which have been documented

Corresponding author: M. K. Hausbeck; E-mail address: hausbec1@msu.edu

* The $e$-Xtra logo stands for "electronic extra" and indicates that Figure 1 appears in color online.

doi:10.1094/PHYTO-100-6-0619

(C) 2010 The American Phytopathological Society throughout the United States $(30,31,33,43)$. Host resistance should be a key component of a disease management strategy for P. capsici on tomato. Regrettably, only a few moderately resistant tomato cultivars are available with commercially acceptable horticultural traits $(4,20)$. More sources of resistance from commercial cultivars or wild species need to be identified. Breeders use wild Solanum spp. as sources of genes controlling traits of economic importance such as fruit characteristics, nutritional content, and general disease resistance (49). Identifying sources of resistant tomato germplasm would aid in the development of cultivars suitable for production in $P$. capsici-infested fields.

The objective of this study was to determine whether different cultivars of S. lycopersicon L., S. pimpinellifolium, S. pennellii, or $S$. habrochaites show resistance to $P$. capsici. Specifically, we sought to determine (i) whether or not commercial tomato or tomato wild relatives could be used as a source of resistance to $P$. capsici, (ii) whether or not infection and disease development were influenced by the $P$. capsici isolates selected, and (iii) the association between lineages of the cultivars and resistance to $P$. capsici. A preliminary report of these findings has been published (46).

\section{MATERIALS AND METHODS}

Tomato cultivars and wild relatives. Forty-two cultivars of tomato and wild relatives (referred collectively as host genotypes) were selected, which included cultivars for fresh market (17 cultivars), processing (17 cultivars), breeding lines (1 cultivar), and 3 wild species ( 7 accessions) provided by either Dr. D. Francis (The Ohio State University), Redgold, Inc. (Elwood, IN), or Seedway, LLC. (Hall, NY) (Table 1). Seed were planted in 72square-cell plastic flats with cell depth of $5.7 \mathrm{~cm}$ and cell width of $4 \mathrm{~cm}$ (Hummert International, Earth City, MO), containing potting soilless media (Baccto Professional Planting Mix; Michigan Peat Company, Houston, TX) and a top layer of medium-grade 
vermiculite (Hummert International). Plugs were grown in a greenhouse at Michigan State University (MSU) for 4 weeks, under approximately $14 \mathrm{~h}$ of day illumination. They were transferred into 2.5-liter square plastic pots (Hummert International) containing the same potting soilless media once they reached an approximate height of $8 \mathrm{~cm}$ and developed three or four true leaves. Plants were allowed to recover from transplant stress for 2 weeks prior to inoculation. For the duration of the experiment, plants were fertilized weekly with Peter's 20-20-20 water-soluble fertilizer (The Scotts Company, Marysville, $\mathrm{OH}$ ) at $200 \mathrm{ppm}$ and irrigated as needed to maintain adequate moisture for plant growth and $P$. capsici disease development. Air temperature and relative humidity data (Table 2) were collected hourly with a Watchdog data logger (450 series; Spectrum Technologies, Inc., East-Plainfield, IL).

Isolate selection and maintenance. $P$. capsici isolates originating from diseased cucurbitaceous and solanaceous crops in Michigan were selected from the culture collection maintained in the laboratory of Dr. Hausbeck at MSU. The selected isolates have shown high virulence (defined as the degree of damage caused to a host by a pathogen) and pathogenicity (defined as the capacity of a pathogen to cause disease on a host genotype) in different hosts $(12,14,45,53)$. Isolates were phenotypically characterized according to mating type (MT) and sensitivity to mefenoxam, an oomycete-specific fungicide (30). Isolates OP97 (A1 MT) and SP98 (A2 MT), from pickling cucumber and pumpkin, respectively, were sensitive to mefenoxam, whereas isolates SFF3 (A2 MT) and 12889 (A1 MT) from pickling cucumber and pepper, respectively, were insensitive.

TABLE 2. Air temperature and relative humidity in the greenhouse during each of the three replicated experiments in which tomato plants were screened for resistance to Phytophthora capsici ${ }^{\mathrm{z}}$

\begin{tabular}{lccccccc}
\hline & \multicolumn{3}{c}{ Air temperature $\left({ }^{\circ} \mathrm{C}\right)$} & & \multicolumn{3}{c}{ Relative humidity $(\%)$} \\
\cline { 2 - 3 } \cline { 6 - 8 } Exp & Avg & Min & Max & & Avg & Min & Max \\
\hline 1 & 18 & 8 & 28 & & 75 & 50 & 100 \\
2 & 19 & 2 & 36 & & 83 & 63 & 103 \\
3 & 18 & 1 & 35 & & 77 & 64 & 90 \\
\hline
\end{tabular}

${ }^{\mathrm{z}}$ Exp $=$ experiment, Avg $=$ average, Min $=$ minimum, and Max $=$ maximum.

TABLE 1. Disease reaction and mean area under the disease progress curve (AUDPC) and percent death values of three experiments in which tomato cultivars and wild relatives were screened for resistance to Phytophthora capsici

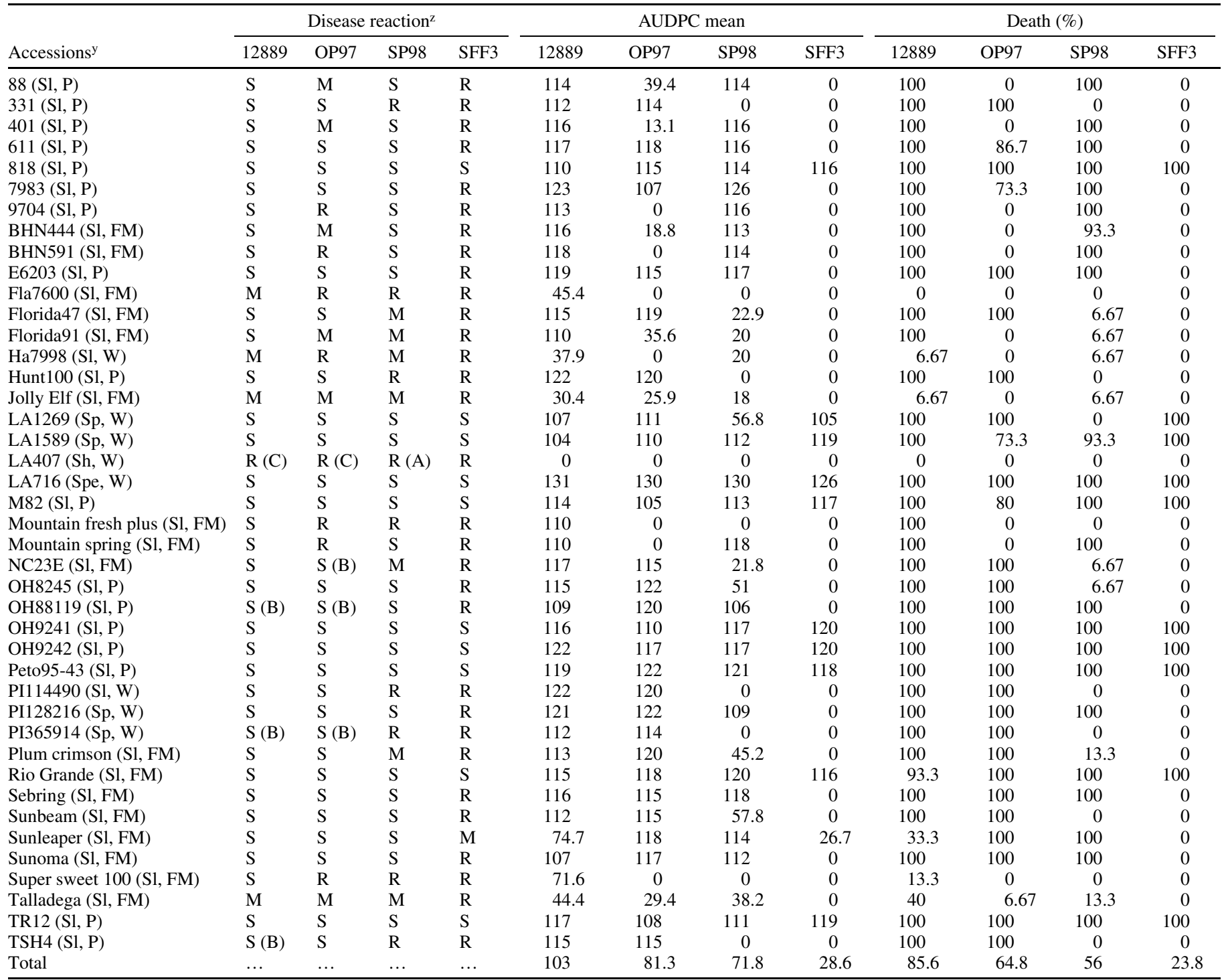

y Letters in parentheses indicate species and type of the accession. S1, Solanum lycopersicon; Sp, S. pimpinellifolium; Spe, S. pennellii; Sh, S. habrochaites; P, processing; FM, fresh market; W, wild.

${ }^{\mathrm{z}}$ Disease reaction. S, susceptible; $\mathrm{M}$, moderately resistant; $\mathrm{R}$, resistant. Letters in parentheses indicate tissue types from which $P$. capsici was recovered in the accession. P. capsici was recovered from root and crown tissue unless otherwise noted: A, roots; B, roots, crown, and secondary stems; and C, P. capsici not recovered. 
Agar plugs from long-term stock cultures (stored at $20^{\circ} \mathrm{C}$ in sterilized microcentrifuge tubes containing $1 \mathrm{ml}$ of sterile water and one sterile hemp seed) of each isolate were transferred onto unclarified V8 juice agar (UCV8; $16 \mathrm{~g}$ of agar, $3 \mathrm{~g}$ of $\mathrm{CaCO}_{3}$, $160 \mathrm{ml}$ of unfiltered $\mathrm{V} 8$ juice, and $840 \mathrm{ml}$ of distilled water) to obtain actively growing cultures, which were maintained at room temperature $\left(21 \pm 2^{\circ} \mathrm{C}\right)$ under constant fluorescent lighting. To ensure that isolates could cause disease, cucumber fruit were disinfested for $5 \mathrm{~min}$ in a $5 \%$ sodium hypochlorite solution, dried at room temperature, and inoculated with each $P$. capsici isolate. A small, superficial wound was made with a sterile needle in the center of each cucumber. Agar plugs ( $7 \mathrm{~mm}$ in diameter) from the margins of actively growing $P$. capsici colonies were placed topside down over each wound. Sterile, capless microcentrifuge tubes were placed over each agar plug and were attached to the fruit with a ring of petroleum jelly. Control cucumber fruit were inoculated as described above using a sterile 7-mm-diameter plug of V8 agar. Cucumber fruit were placed in aluminum trays containing wet paper towels and covered with plastic wrap to maintain high relative humidity and incubated at room temperature $\left(21 \pm 2^{\circ} \mathrm{C}\right)$. Symptomatic cucumber tissue $(0.5 \mathrm{~cm})$ was excised and transferred to UCV8 and maintained under the same culture conditions as described above. Axenic cultures of each isolate were obtained from the infected cucumber tissue and these were transferred to new UCV8 plates weekly until use.

Inoculum preparation and root inoculation. $P$. capsici-infested millet seed was prepared as inoculum. Millet seed (100 g) was mixed with L-asparagine $(0.08 \mathrm{~g})$ and water $(72 \mathrm{ml})$ in a $500-$ $\mathrm{ml}$ Erlenmeyer flask, capped with aluminum foil, autoclaved for two consecutive cycles, and shaken to homogenize the mixture. The sterilized millet seed was inoculated with four 7-mm-diameter agar plugs from actively growing $P$. capsici cultures. The inoculated millet seed was incubated at room temperature under constant fluorescent lighting for 4 weeks.

Inoculation of the plants was achieved by carefully inserting $1 \mathrm{~g}$ of millet seed infested with one of four $P$. capsici isolates (OP97, SFF3, SP98, and 12889) directly into the soilless media adjacent to each plant crown, avoiding root or crown injury. For each isolate, five replicate plants of each tomato genotype were inoculated. Five additional control plants of each tomato genotype were inoculated with uninfested millet seed containing sterile V8 agar plugs. This experiment was conducted three times.

Disease assessment. Disease assessment was conducted daily for 5 weeks and was initiated 1 day following inoculation. Disease progression was recorded for each plant using the following scale: $0=$ no symptoms, $1=1$ to $30 \%$ wilting, $2=31$ to $50 \%$ wilting, $3=51$ to $70 \%$ wilting, $4=71$ to $90 \%$ wilting, and $5=>90 \%$ wilting or dead plant (Fig. 1). The area under the disease progress curve (AUDPC) was calculated by inserting the disease score into the equation by Shaner and Finney (56) to describe the cumulative plant susceptibility throughout the experiments. The percentage of death and the incidence of $P$. capsici recovered from roots, crowns, secondary stems (equivalent of branches in a woody plant), and leaves were determined. The plant height was measured at the end of the experiment for host genotypes that appeared resistant based on AUDPC values. Tomato genotypes were considered to be resistant to $P$. capsici if disease caused by the four isolates used in our study did not result in serious damage to the plants, as indicated by mean AUDPC values of three replicated experiments. Resistant, moderately resistant, and susceptible genotypes to each $P$. capsici isolate included those with mean AUDPC values <10, 10 to 50, and >50, respectively.

Pathogen isolation. Control and inoculated plants were gently rinsed to remove the soilless medium and other residues, dipped into 5\% sodium hypochlorite for $1 \mathrm{~min}$ to surface disinfest, rinsed with sterile water, and air dried. Three sections of root, crown, secondary stem, and leaf tissue were excised from each plant and plated onto benomyl, ampicillin, rifampicin, and pentachloronitrobenzene (BARP)-amended UCV8 (32) under sterile conditions.

Colonies suspected to be $P$. capsici were transferred to new BARP-amended UCV8 plates. Axenic cultures were incubated for 7 days on UCV8 with constant fluorescent lighting under ambient laboratory conditions $\left(21 \pm 2{ }^{\circ} \mathrm{C}\right)$. Cultures were positively identified as $P$. capsici based on morphological characteristics described by Waterhouse (64). Isolates were characterized for compatibility type and mefenoxam resistance as previously described (30) to compare the phenotype of the isolate obtained with the original inoculum.

DNA extraction and molecular confirmation of infection. Samples of root and crown tissue from inoculated resistant and moderately resistant tomato genotypes were collected at the end of the experiment, gently rinsed to remove the soilless medium and other residues, dipped into 5\% sodium hypochlorite for $1 \mathrm{~min}$ to surface disinfect, rinsed with sterile water, air dried, and ground in liquid nitrogen. Genomic DNA was extracted from approximately $1 \mathrm{~g}$ of ground tissue using the DNeasy DNA extraction kit (Qiagen, Valencia, CA) according to the manufacturer's instructions. DNA was quantified using the NanoDrop ND 1000 spectrophotometer and NanoDrop 2.4.7c software (NanoDrop Technologies Inc., Wilmington, DE). Two specific primers for $P$. capsici were used for polymerase chain reaction (PCR): one forward primer (CAPFW; 5'TTTAGTTGGGGGTCTTGTACC3') and one reverse primer (CAPRV2; 5'TACGGTTCACCAGC CCATCA3') (45). Reactions were performed in a total volume of $25 \mu \mathrm{l}$ and contained $1 \mu \mathrm{l}$ of DNA, $5 \mu \mathrm{l}$ of $5 \times$ PCR reaction buffer, $1.25 \mu \mathrm{l}$ of $25 \mu \mathrm{M} \mathrm{MgCl}_{2}, 0.5 \mu \mathrm{l}$ of $10 \mu \mathrm{M}$ dNTP mix, $0.7 \mu \mathrm{l}$ of Taq DNA polymerase (Invitrogen, Carlsbad, CA), $1 \mu \mathrm{l}$ each of $10 \mu \mathrm{M}$ primer (MSU Macromolecular Structure Facility, East Lansing, $\mathrm{MI}$ ), and $14.6 \mu \mathrm{l}$ of sterile water. The PCR reaction was performed in a programmable thermal cycler (Eppendorf, Westbury, $\mathrm{NY}$ ) starting with $3 \mathrm{~min}$ of denaturation at $94^{\circ} \mathrm{C}$; followed by 45 cycles at $94^{\circ} \mathrm{C}$ for $30 \mathrm{~s}$, annealing at $56^{\circ} \mathrm{C}$ for $30 \mathrm{~s}$, and extension at $72^{\circ} \mathrm{C}$ for $60 \mathrm{~s}$; with a final extension step of $10 \mathrm{~min}$ at $72^{\circ} \mathrm{C}$. PCR products were analyzed by electrophoresis in $2 \%(\mathrm{wt} / \mathrm{vol})$ agarose gel in $0.5 \times$ Tris-borate-EDTA buffer (35), stained with ethidium bromide $(5 \mu \mathrm{g} / \mathrm{ml})$ for visualization and compared with a 100-bp ladder (Invitrogen) to determine amplicon size. Controls with $P$. capsici DNA and tomato DNA were included.

Amplified fragment length polymorphism analysis. Samples (1 g) of 4-week-old healthy tomato tissue were collected and ground in liquid nitrogen. Genomic DNA was extracted and quantified as described above. All PCR reactions were performed with a programmable thermal cycler (Eppendorf). DNA ( $\approx 500 \mathrm{ng}$ ) was subjected to a restriction/ligation reaction, preselective amplification, and selective amplifications using the amplified fragment length polymorphism (AFLP) kit for regular plant genomes (Applied Biosystems, Foster City, CA) according to the manufacturer's instructions. Selective amplifications with the selective primers MseI-CAA and EcoRI-ACA, and MseI-CAA and EcoRIAAG, were performed. Selective PCR products were purified with ExoSAP-IT (Affymetrix, Inc., Santa Clara, CA) following the manufacturer's instructions. Products labeled with different colored dyes were analyzed at the MSU Research Technology Support Facility (RTSF) using the ABI PRISM 3130 Genetic Analyzer and compared with a 500-carboxy-X-rhodamine (ROX) size standard (Applied Biosystems) following the manufacturer's instructions. Results were prepared for analysis by the RTSF in the form of electropherograms using GeneScan 3.1 analysis software (Applied Biosystems). AFLP fragments were scored manually as present $=1$ or absent $=0$ using PeakScanner 1.0 (Applied Biosystems). Only DNA-labeled fragments with a size $\geq 70$ bp were scored to obtain a binary character matrix. Once fragments of appropriate size were identified, only labeled fragments with a fluorescence signal $\geq 300$ relative fluorescence units $(\mathrm{rtf})$ in at 
least one cultivar were scored for presence or absence in the rest of the cultivars. The binary matrix, consisting of combined data of both primer sets, was analyzed to generate an unweighted pairgroup method with arithmetic mean (UPGMA) distance tree and a pairwise genetic distance matrix using PAUP*4.0b10 (60).

Statistical analyses. All statistical analyses were performed using the SAS statistical package (version 9.1; SAS Institute Inc., Cary, NC). The experiment was arranged in a split-plot with experiment as a blocking factor, isolates as whole plots, and host genotypes as subplots arranged in a randomized complete block design. The AUDPC, incidence, and plant height values of the three replicated experiments were used for statistical analyses. AUDPC data from control plants were removed from the data set prior to statistical analyses because no infection occurred and no symptoms developed. AUDPC and plant height data were normalized by square root transformation, and the residuals followed the assumptions of all statistical tests performed. The percent death was not included for statistical analysis because the residuals did
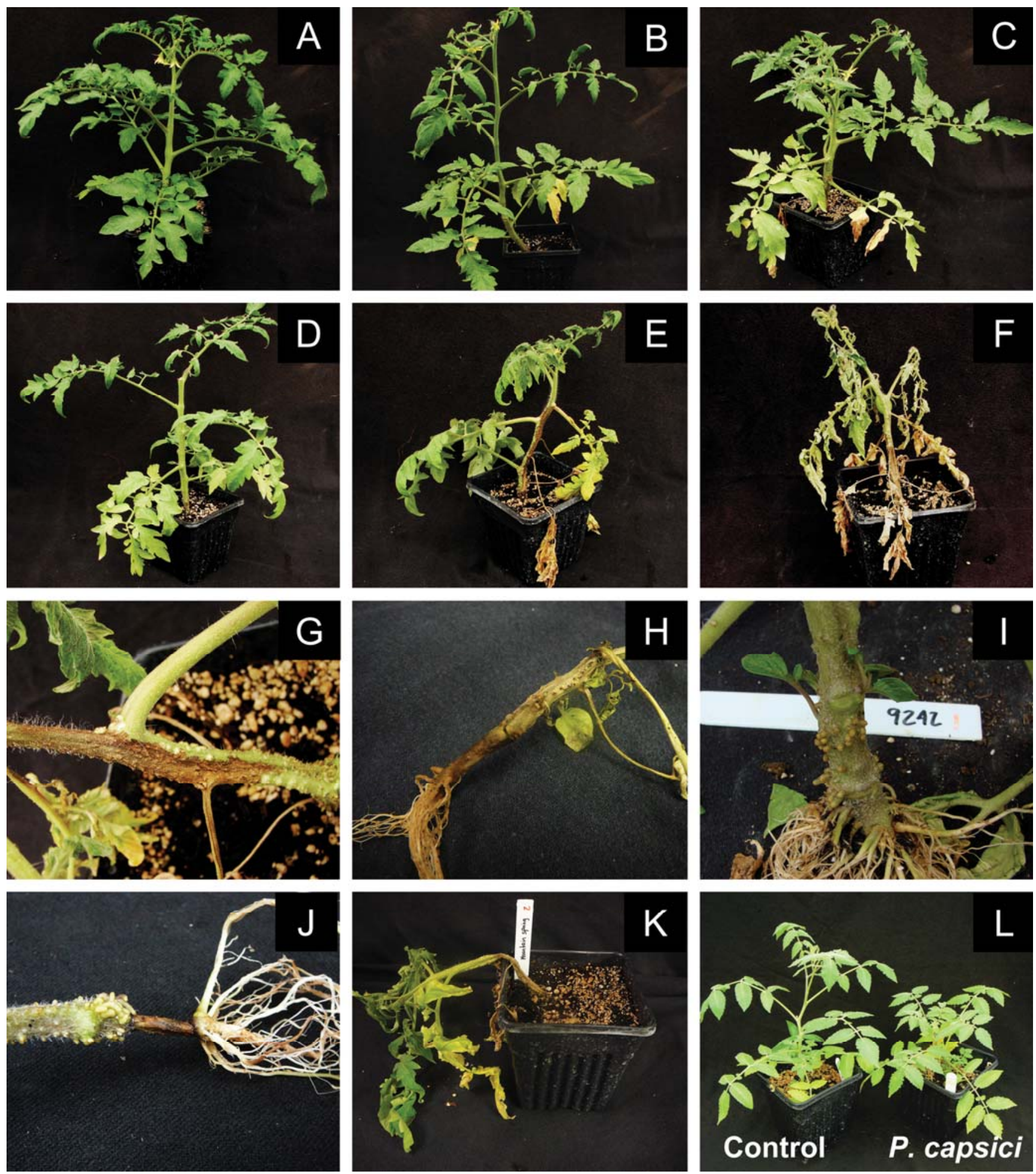

Fig. 1. Symptoms of Phytophthora capsici root rot on tomato and wilting scale used in plant evaluations. A, $0=$ no symptoms, healthy plant; $\mathbf{B}, 1=1$ to $30 \%$ wilting; C, $2=31$ to $50 \%$ wilting; D, $3=51$ to $70 \%$ wilting; $\mathbf{E}, 4=71$ to $90 \%$ wilting; and $\mathbf{F}, 5=$ more than $90 \%$ wilting or dead plant. G, Stem canker. H, Watersoaked lesions in the stem, rotted crown, and rotted and discolored roots. I, Secondary roots. J, Girdling. K, Damping-off. L, Stunting. 
not follow the assumptions required for statistical tests. Data were subjected to analysis of variance (ANOVA) using the PROC MIXED, PROC GLM, and PROC GLIMMIX procedures of SAS. Correlation between UPGMA cluster (defined by the genetic distance matrix) and resistance to $P$. capsici was determined using the PROC CORR procedure. Multiple comparisons among the means were conducted using $t$ tests (least significant difference [LSD]) when effects were found to be statistically significant at $P=0.05$ in ANOVA.

\section{RESULTS}

Initial disease symptoms occurred within 4 days following inoculation in susceptible and some moderately resistant tomato genotypes for each $P$. capsici isolate. In susceptible genotypes, wilting was observed in the lower leaves within the first week and progressed upward until the entire plant wilted. External, dark discoloration of the crowns and crown rot were observed on some plants and the root system was often discolored. Subsequently, stem cankers and girdling developed, and some plants shriveled at the soil level (Fig. 1). Brown, water-soaked lesions were visible on roots and crowns of symptomatic plants within 6 days. Plant death was observed as early as 7 to 8 days following inoculation in some host genotypes but was not visible until 4 weeks after inoculation for others. Moderately resistant cultivars showed mild wilting 7 to 8 days following inoculation but quickly recovered. Some plants continued to grow and maintain healthy tops by regenerating an extensive number of secondary roots (Fig. 1). Resistant genotypes did not show wilting after inoculation or production of secondary roots. Some resistant and moderately resistant host genotypes also presented significant stunting.

Disease severity differed significantly depending on the interaction effects between isolate and tomato genotype (ANOVA, $P<0.0001)$. Responses to individual isolates varied from no symptoms to $100 \%$ wilting and death of inoculated plants. Isolate 12889 was more pathogenic on tomato genotypes than other isolates used in plant inoculations according to trends in AUDPC and percent plant death (Table 1). Interaction effects were not found between repeated experiments and isolate (ANOVA, $P=$ $0.5178)$. Effects due to differences between experiments were not significant (ANOVA, $P=0.2926$ ). Only one of the genotypes (LA407) did not show wilting or any other symptoms other than stunting following inoculation with the four different $P$. capsici isolates (Table 1). Four of the host genotypes (Fla7600, Ha7998, Jolly Elf, and Talladega) developed moderate symptoms with $<12 \%$ plant death (Table 1). LA716 was the most susceptible genotype in our study, exhibiting the highest AUDPC values and $100 \%$ plant death (Table 1).

The pathogen was isolated from all surviving susceptible, moderately resistant, and resistant genotypes at the end of the experiment and from plants that died over the course of the experiment. $P$. capsici was isolated from symptomatic plants of the moderately resistant genotypes Fla7600, Ha7998, Jolly Elf, and Talladega and from the roots of the resistant genotype LA407 (Table 1). P. capsici infection in the moderately resistant and resistant genotypes was confirmed by performing $P$. capsicispecific PCR of DNA from surface-sterilized, inoculated root and crown tissue to confirm that the very low recovery of $P$. capsici from LA407 by culturing techniques was not due to an escape. All $P$. capsici-inoculated moderately resistant and resistant genotypes were positive for presence of $P$. capsici in root or crown tissue. Significant differences in pathogen incidence were found among different plant parts (PROC GLIMMIX and LSD, $P<$ $0.0001)$. Interaction effects were found between the isolate used and tomato genotype for incidence data (ANOVA, $P<0.0001$ ). Interaction effects were not found between experiments and isolate (ANOVA, $P=0.9994$ ). Effects due to differences between repeated experiments were not significant (ANOVA, $P=0.9442$ ). Although the secondary stems and leaves exhibited wilting in all experiments, the pathogen was rarely recovered from secondary stems and never recovered from leaves (Table 3 ). The phenotype (mating type and mefenoxam resistance) of recovered isolates was confirmed and matched the phenotype of the isolate used as inoculum (data not shown). The control plants remained asymptomatic and the pathogen was not isolated from any control plant tissue. Clean cultures were obtained from $94 \%$ of the original cultures isolated from tomato tissue.

Stunting was observed in several tomato genotypes, including some of the moderately resistant and resistant candidates (Fig. 1L). Plant height was measured for surviving inoculated moderately resistant and resistant genotypes and the corresponding control plants for those host genotypes at the end of the experiment. Generally, plants inoculated with one of the four $P$. capsici isolates were significantly shorter than the corresponding control plants, although the interaction between isolate and tomato genotype was significant (ANOVA, $P<0.0001$ ). Pairwise comparisons between each tomato genotype inoculated with a particular isolate and the corresponding control plant indicated that genotypes Fla7600 and Jolly Elf did not show significant differences in plant height regardless of isolate (LSD, $P>0.05$ ) (Table 4). Interaction effects were not found between repeated experiments and isolate (ANOVA, $P=0.5478$ ). Effects due to differences between experiments were not significant (ANOVA, $P=0.0600$ ).

TABLE 4. Probability $(P)$ values for significance of differences in plant height between inoculated plants and their corresponding controls for tomato genotypes resistant and moderately resistant to Phytophthora capsici

\begin{tabular}{lcccc}
\hline & \multicolumn{4}{c}{$P$ value $^{z}$} \\
\cline { 2 - 5 } Cultivar & 12889 & \multicolumn{1}{c}{ OP97 } & SP98 & SFF3 \\
\hline Fla7600 & 0.8164 & 0.5798 & 0.0744 & 0.5324 \\
Ha7998 & $0.0093^{*}$ & $0.0004^{*}$ & $<0.0001^{*}$ & $<0.0001^{*}$ \\
LA407 & $0.0402^{*}$ & $0.0048^{*}$ & $<0.0001^{*}$ & $<0.0001^{*}$ \\
Jolly Elf & 0.0745 & 0.1681 & 0.1567 & 0.5653 \\
Talladega & $<0.0001^{*}$ & $0.0327^{*}$ & $0.0002^{*}$ & 0.8062 \\
\hline
\end{tabular}

${ }^{\mathrm{z}}$ Asterisk (*) indicates means significantly different from the control (least significant difference); analyses included data from three experiments.

TABLE 3. Incidence of Phytophthora capsici isolates obtained from different parts of the symptomatic tomato plants sampled in each of three replicated experiments

\begin{tabular}{|c|c|c|c|c|c|c|c|c|}
\hline \multirow[b]{2}{*}{ Experiment } & \multirow[b]{2}{*}{ No. of plants ${ }^{\mathrm{v}}$} & \multirow[b]{2}{*}{ No. of isolates ${ }^{\mathrm{w}}$} & \multicolumn{2}{|c|}{ Isolates obtained $(\%)^{\mathrm{xy}}$} & \multicolumn{4}{|c|}{ Incidence of $P$. capsici $(\%)^{\mathrm{xz}}$} \\
\hline & & & Root & Crown & Root & Crown & Secondary stem & Leaf \\
\hline 1 & 570 & 910 & $470(51.6)$ & $440(48.4)$ & $488(50.7)$ & $471(48.8)$ & $5(0.5)$ & $0(0)$ \\
\hline 2 & 583 & 903 & $458(50.7)$ & $445(49.3)$ & $483(50)$ & $479(49.6)$ & $4(0.4)$ & $0(0)$ \\
\hline 3 & 579 & 890 & $459(51.6)$ & $431(48.4)$ & $488(51.3)$ & $458(48.1)$ & $6(0.6)$ & $0(0)$ \\
\hline
\end{tabular}

${ }^{\mathrm{v}}$ Number of symptomatic plants sampled.

${ }^{\mathrm{w}}$ Total number of isolates.

${ }^{x}$ Numbers in parentheses correspond to percentage values and numbers not in parentheses are the raw values.

y As determined by axenic pathogen isolation at the conclusion of the experiment.

${ }^{\mathrm{z}}$ As determined by observation of growth of the pathogen isolated from plant tissue. 
The MseI-CAA and EcoRI-ACA, and MseI-CAA and EcoRIAAG, primer pairs yielded a total of 104 and 120 AFLP markers, respectively. Of the total 224 AFLP markers obtained, 126 corresponded to labeled fragments with a size $\geq 70 \mathrm{bp}$ and a signal $\geq 300 \mathrm{rtf}$ that were scored for presence and absence in the tomato genotypes and included in the analyses. In all, 4 of these markers were polymorphic only among Solanum spp. (2\% of interspecific polymorphism), 31 markers had variation among Solanum spp. and S. lycopersicon cultivars (14\% of inter and intraspecific polymorphism), 11 markers were polymorphic only for $S$. lycoper- sicon cultivars ( $5 \%$ of intraspecific polymorphism), and the other 80 markers were present in all tomato genotypes (79\% monomorphic). Seven similarity groups, including four main clusters (A, B, C, and F) and three clades formed by single genotypes (D, E, and G) with $>80 \%$ similarity, were obtained after genetic distance analysis of the AFLP data (Fig. 2). The UPGMA tree topology does not indicate a subdivision of clusters based on susceptibility to $P$. capsici. Statistical analysis found no significant correlation between cluster and susceptibility to $P$. capsici $(P>0.05)$.
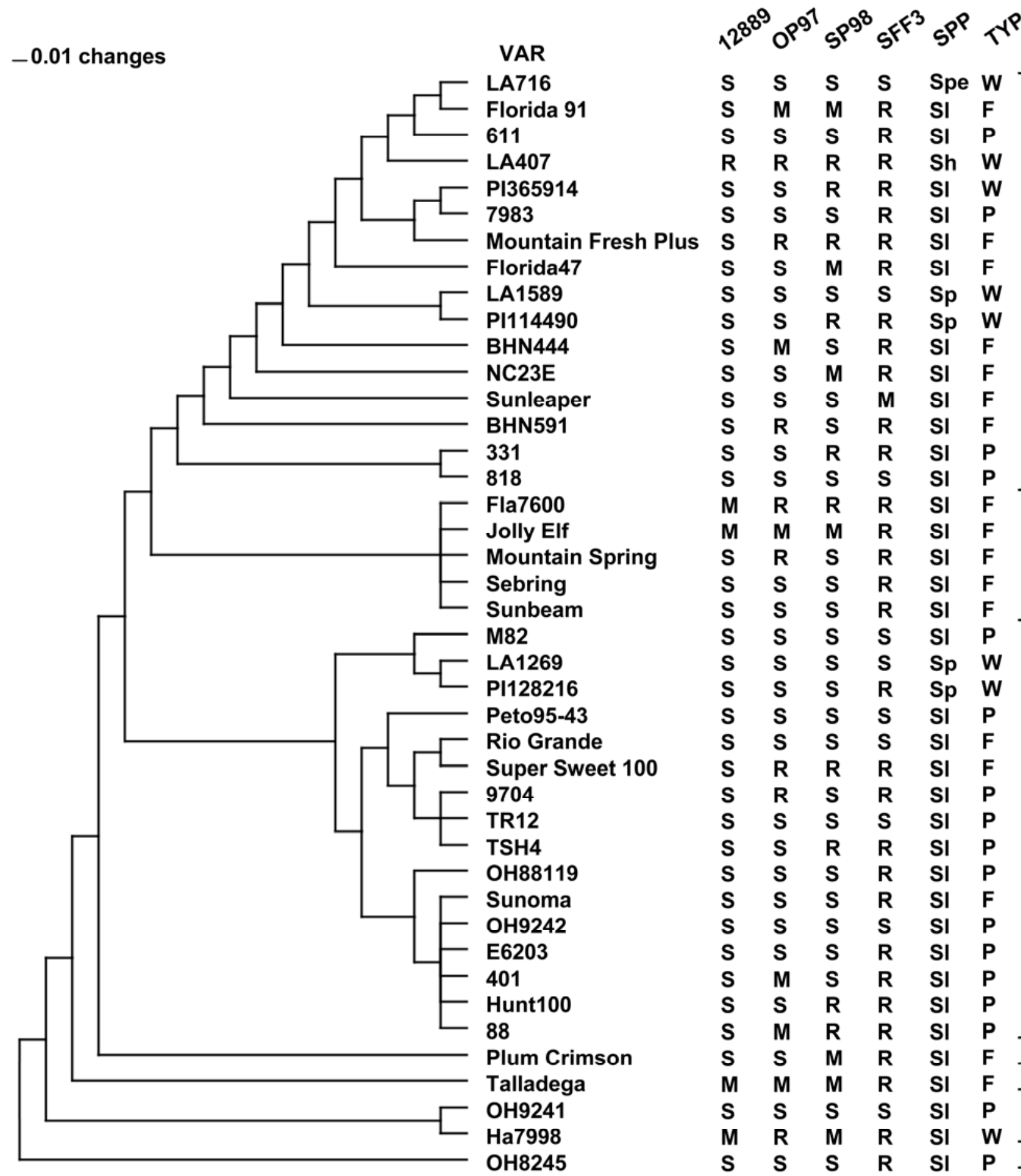

\begin{tabular}{|c|c|c|c|c|c|}
\hline $\mathbf{S}$ & $\mathbf{S}$ & 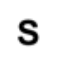 & $\mathbf{S}$ & Spe & W \\
\hline $\mathbf{S}$ & $\mathbf{M}$ & $\mathbf{M}$ & $\mathbf{R}$ & SI & $\mathbf{F}$ \\
\hline $\mathbf{S}$ & $\mathbf{S}$ & $\mathbf{S}$ & $\mathbf{R}$ & SI & $\mathbf{P}$ \\
\hline $\mathbf{R}$ & $\mathbf{R}$ & $\mathbf{R}$ & $\mathbf{R}$ & Sh & $\mathbf{W}$ \\
\hline $\mathbf{S}$ & $\mathbf{S}$ & $\mathbf{R}$ & $\mathbf{R}$ & SI & $\mathbf{W}$ \\
\hline $\mathbf{S}$ & $\mathbf{S}$ & $\mathbf{S}$ & $\mathbf{R}$ & SI & $\mathbf{P}$ \\
\hline $\mathbf{S}$ & $\mathbf{R}$ & $\mathbf{R}$ & $\mathbf{R}$ & SI & $\mathbf{F}$ \\
\hline $\mathbf{S}$ & $\mathbf{S}$ & $\mathbf{M}$ & $\mathbf{R}$ & SI & $\mathbf{F}$ \\
\hline $\mathbf{S}$ & $\mathbf{S}$ & $\mathbf{S}$ & $\mathbf{S}$ & Sp & $\mathbf{W}$ \\
\hline $\mathbf{S}$ & $\mathbf{S}$ & $\mathbf{R}$ & $\mathbf{R}$ & Sp & $\mathbf{W}$ \\
\hline $\mathbf{S}$ & M & $\mathbf{S}$ & $\mathbf{R}$ & SI & $\mathbf{F}$ \\
\hline $\mathbf{S}$ & $\mathbf{S}$ & $\mathbf{M}$ & $\mathbf{R}$ & SI & $F$ \\
\hline $\mathbf{S}$ & $\mathbf{S}$ & $\mathbf{S}$ & $\mathbf{M}$ & SI & $\mathbf{F}$ \\
\hline $\mathbf{S}$ & $\mathbf{R}$ & $\mathbf{S}$ & $\mathbf{R}$ & SI & $\mathbf{F}$ \\
\hline $\mathbf{S}$ & $\mathbf{S}$ & $\mathbf{R}$ & $\mathbf{R}$ & SI & $\mathbf{P}$ \\
\hline $\mathbf{S}$ & $\mathbf{S}$ & $\mathbf{S}$ & $\mathbf{S}$ & SI & $\mathbf{P}$ \\
\hline M & $\mathbf{R}$ & $\mathbf{R}$ & $\mathbf{R}$ & SI & $F$ \\
\hline M & $\mathbf{M}$ & $\mathbf{M}$ & $\mathbf{R}$ & SI & $\mathbf{F}$ \\
\hline $\mathbf{S}$ & $\mathbf{R}$ & $\mathbf{S}$ & $\mathbf{R}$ & SI & $F$ \\
\hline $\mathbf{S}$ & $\mathbf{S}$ & $\mathbf{S}$ & $\mathbf{R}$ & SI & $F$ \\
\hline $\mathbf{S}$ & $\mathbf{S}$ & $\mathbf{S}$ & $\mathbf{R}$ & SI & $F$ \\
\hline $\mathbf{S}$ & $\mathbf{S}$ & $\mathbf{S}$ & $\mathbf{S}$ & SI & $\mathbf{P}$ \\
\hline $\mathbf{S}$ & $\mathbf{S}$ & $\mathbf{S}$ & $\mathbf{s}$ & Sp & $\mathbf{W}$ \\
\hline $\mathbf{S}$ & $\mathbf{S}$ & $\mathbf{S}$ & $\mathbf{R}$ & Sp & $\mathbf{W}$ \\
\hline $\mathbf{S}$ & $\mathbf{S}$ & $\mathbf{S}$ & $\mathbf{S}$ & SI & $\mathbf{P}$ \\
\hline $\mathbf{S}$ & $\mathbf{S}$ & $\mathbf{S}$ & $\mathbf{S}$ & SI & $F$ \\
\hline $\mathbf{S}$ & $\mathbf{R}$ & $\mathbf{R}$ & $\mathbf{R}$ & SI & $F$ \\
\hline $\mathbf{S}$ & $\mathbf{R}$ & $\mathbf{S}$ & $\mathbf{R}$ & SI & $\mathbf{P}$ \\
\hline $\mathbf{S}$ & $\mathbf{S}$ & $\mathbf{S}$ & $\mathbf{S}$ & SI & $\mathbf{P}$ \\
\hline $\mathbf{S}$ & $\mathrm{S}$ & $\mathbf{R}$ & $\mathbf{R}$ & SI & $\mathbf{P}$ \\
\hline $\mathbf{S}$ & $\mathbf{S}$ & $\mathbf{S}$ & $\mathbf{R}$ & SI & $\mathbf{P}$ \\
\hline $\mathbf{S}$ & $\mathbf{S}$ & $\mathbf{S}$ & $\mathbf{R}$ & SI & $F$ \\
\hline S & $\mathbf{S}$ & $\mathbf{S}$ & $\mathbf{S}$ & SI & $\mathbf{P}$ \\
\hline S & $\mathbf{S}$ & $\mathbf{S}$ & $\mathbf{R}$ & SI & $\mathbf{P}$ \\
\hline s & M & $\mathbf{S}$ & $\mathbf{R}$ & SI & $\mathbf{P}$ \\
\hline $\mathbf{S}$ & S & $\mathbf{R}$ & $\mathbf{R}$ & SI & $\mathbf{P}$ \\
\hline $\mathbf{S}$ & $\mathbf{M}$ & $\mathbf{R}$ & $\mathbf{R}$ & SI & $\mathbf{P}$ \\
\hline S & $\mathbf{S}$ & $\mathbf{M}$ & $\mathbf{R}$ & SI & $\mathbf{F}$ \\
\hline M & $M$ & $\mathbf{M}$ & $\mathbf{R}$ & SI & $\mathbf{F}$ \\
\hline $\mathbf{S}$ & $\mathrm{S}$ & $\mathbf{S}$ & $\mathbf{S}$ & SI & $\mathbf{P}$ \\
\hline M & $\mathbf{R}$ & $\mathbf{M}$ & $\mathbf{R}$ & SI & w \\
\hline & $S$ & $\mathrm{~S}$ & $\mathbf{R}$ & SI & $\mathbf{P}$ \\
\hline
\end{tabular}

Fig. 2. Amplified fragment length polymorphism distance tree of tomato cultivars and wild relatives screened for resistance to Phytophthora capsici. Susceptibility to $P$. capsici 12889 , OP97, SP98, and SFF3 ( $\mathrm{S}=$ susceptible, $\mathrm{M}=$ moderately resistant, and $\mathrm{R}=$ resistant), tomato species $(\mathrm{SPP}: \mathrm{Sl}=$ Solanum lycopersicon, $\mathrm{Sp}=$ S. pinpinelifolium, $\mathrm{Spe}=$ S. pennellii, and $\mathrm{Sh}=$ S. habrochaites $)$, and type of cultivar $(\mathrm{TYP}: \mathrm{F}=$ fresh market, $\mathrm{P}=$ processing, and $\mathrm{W}=$ wild $)$ are indicated for each cultivar. A, B, C, D, E, F, and G, correspond to similarity groups obtained in unweighted pair-group method with arithmetic mean clustering analysis. 


\section{DISCUSSION}

Early infections by $P$. capsici on tomato cause plant dampingoff, whereas later infections cause root and crown rot on mature plants (21). Phytophthora root rot results in wilting with brownto-black cankers on the lower stems, blackening of the vascular tissue, and root rot (29), which may initiate the development of secondary roots (4). Infected plants may become stunted and wilted (21), as they did in our study. Plants showing quantitative resistance to Phytophthora root rot have been reported to develop and maintain healthy canopies by regenerating an extensive number of secondary roots, a response that is most likely polygenic (4). In this experiment, several host genotypes produced secondary roots that emerged just above a stem canker or crown rot lesion but many of them still died, possibly because the response was not fast enough. The moderately resistant genotypes Talladega and Jolly Elf produced secondary roots in some cases and maintained healthy canopies throughout the duration of the experiment. The resistant cv. LA407 did not show this response. Symptoms developed more slowly on the moderately resistant genotypes Fla7600, Ha7998, Jolly Elf, and Talladega than on the other genotypes tested. In general, the response of moderately resistant tomato genotypes to Phytophthora root and crown rot was quantitative rather than qualitative, as observed in the $P$. capsici-pepper interaction (26). In some cases, such as the resistant genotype LA407 or the susceptible genotype LA716, the response is more qualitative because there appeared to be no disease in LA407 plants but all LA716 plants died.

The success of greenhouse screening depends on the plant's age and resistance level, inoculum quality or quantity, inoculation technique, and post inoculation environmental conditions. These factors may influence quantitative responses such as resistance to $P$. capsici. For this study, environmental conditions in the greenhouse were not always ideal for plant and pathogen growth due to low minimum air temperatures $\left(1\right.$ to $\left.2^{\circ} \mathrm{C}\right)$ and high maximum air temperatures $\left(35\right.$ to $\left.36^{\circ} \mathrm{C}\right)$ in experiments 2 and 3 . The minimum, optimum, and maximum temperatures for growth of $P$. capsici are 10,28 , and $>35^{\circ} \mathrm{C}$, respectively (9). Tomato plants prefer warmer temperatures $\left(18\right.$ to $\left.26^{\circ} \mathrm{C}\right)$ for normal plant development, growth, and fruit set (24), and become sensitive to biotic and abiotic stress at temperatures $<10^{\circ} \mathrm{C}$ or $>35^{\circ} \mathrm{C}$ (24). Nonetheless, environmental conditions did not seem to alter disease development and average air temperatures were suitable for plant and pathogen growth. Furthermore, there were no statistically significant interactions with experiment; therefore, any effects on disease development appear to have been constant across isolates and host genotypes.

Resistance to $P$. capsici under greenhouse conditions may differ from the responses observed under field conditions due to the quantitative nature of the trait. The soilless medium used in this study may have influenced resistance to $P$. capsici, and the responses observed in the greenhouse may not be consistent in the field, depending on soil type, soil microbial community composition, $\mathrm{pH}$, and other factors. Other studies on $P$. capsici (27) and other soilborne pathogens $(16,39)$ have shown variable results, with observations of increased or decreased disease severity depending on the soil type, soilless substrates, or treatments used. To our knowledge, none of these studies have determined the influence of soilless medium on $P$. capsici. However, if soilless medium effects on $P$. capsici exist, they were consistent throughout the experiments and did not appear to inhibit disease development.

The type and quantity of inoculum used can also affect disease severity in greenhouse and field studies $(14,15,45)$. The milletseed inoculation technique was effective for establishing $P$. capsici infection on susceptible tomato genotypes in the greenhouse, as has been reported in previous studies with other host plants $(12,45)$. The millet-seed inoculum for our experiments contained only mycelia and sporangia, whereas Michigan fields infested with $P$. capsici have been found to contain oospores $(30,31)$. Oospores allow the pathogen to overwinter, may persist for years $(18,32)$, and are primary inocula (18). For our experiments, we used $P$. capsici propagules that constitute secondary inocula and cause tomato field epidemics (21). Studies replicating our greenhouse experiment in $P$. capsici-infested fields would help establish the influence of inoculum type on disease severity as well as the transferability of greenhouse results to field conditions.

All P. capsici isolates tested caused disease on some plants, although there was a significant isolate-tomato genotype interaction. Isolate 12889 produced symptoms in more host genotypes, followed by OP97, SP98, and SFF3. When these isolates were tested on pepper in an earlier study (15), 12889 was also found to be the most pathogenic; however, no differences were detected when the isolates were tested on cucumber fruit (14) and Fraser fir (45). As early as 1972, field populations of $P$. capsici from solanaceous and cucurbitaceous hosts were shown to differ in pathogenicity (44); other reports of this variation have been published for several hosts $(5,26,40,41,48,50)$, including tomato, where an interaction between host and isolate was also reported $(17,20)$. It has been suggested in previous studies that $P$. capsici isolates obtained from the family Solanaceae have increased pathogenicity on Solanaceous hosts compared with isolates obtained from cucurbits $(19,34,50)$. Further studies that include more isolates are needed to clarify whether P. capsici 12889 has increased pathogenicity in tomato and pepper genotypes because it was isolated from another solanaceous host or whether the pathogenicity is due to an isolate-specific effect.

The differences in pathogenicity found between these Michigan isolates have significant implications for local plant breeding programs. Breeding for resistance in pepper against $P$. capsici has been challenging due to the diversity of pathogen populations, the existence of different physiological races within $P$. capsici in the United States $(40,63)$, and the various complex modes of inheritance of resistance reported for pepper (47). Similarly, for tomato, studies are needed to characterize $P$. capsici populations, define races that infect tomato, and determine their spatial structure in order to intelligently deploy tomato resistance in Michigan. Nonetheless, in this study, tomato genotypes LA407, Fla7600, Ha7998, Jolly Elf, and Talladega showed high or moderate resistance to all of the isolates tested and could be used as a starting point to find resistance to Michigan $P$. capsici isolates.

Our data indicated that the four isolates tested probably represent different races. Nonetheless, the tomato genotypes should be tested against a larger number of isolates, particularly those obtained from tomato, to better understand this interaction and to eventually develop a system with host differentials for identifying races, as has been described for pepper (62). No resistant control was used in our study because, to the best of our knowledge, there is no standard tomato resistant to $P$. capsici. When screening pepper cultivars for resistance to $P$. capsici, the $\chi^{2}$ test has been used to determine relative resistance of pepper lines by comparison with standard resistant peppers such as CM334 (62). Our experiments identified the resistant genotype LA407; thus, a similar approach to the one used in the $P$ capsici-pepper interaction can now be applied to future $P$. capsici-tomato interaction studies.

Significant differences in pathogen incidence were found among different plant parts, possibly indicating that more than one mechanism of host resistance may be involved. In pepper, it has been observed that resistance to $P$. capsici is due to different genetic controls depending on tissue type $(61,63)$. In our study, the pathogen was successfully recovered from roots and crowns of all symptomatic, root-inoculated seedlings. P. capsici can be difficult to isolate from certain tissue types, such as mature pepper stems (M. K. Hausbeck, unpublished data), asparagus (55), or Fraser fir tissue (45), but was easily isolated from 
symptomatic tomato plants in our experiments. However, PCR was useful because it confirmed that the inability to detect $P$. capsici in LA407 using culture techniques was not due to an escape. In previous studies, PCR was able to detect false negatives after a lack of $P$. capsici detection by culturing techniques in pepper plants when symptoms and signs where not obvious (51). Genotypes Ha7998 and Talladega were both stunted as a result of $P$. capsici infection; yet, when Talladega was inoculated with SFF3, the least pathogenic isolate in our study, the plants did not show stunting. Stunting in resistant and moderately resistant genotypes indicates that the pathogen was directly limiting plant growth. However, it is not known whether stunting would occur in nature on a resistant genotype or was the result of the relatively axenic conditions of the experiment.

Wild species of tomato can be a valuable source of economically important traits, including resistance to diverse pathogens for the improvement of cultivated tomato crops (10). In our study, we found that $S$. habrochaites LA407 was resistant to the four $P$. capsici isolates used. Interestingly, LA407 was resistant to bacterial canker caused by Clavibacter michiganensis subsp. michiganensis $(13,25)$ and early blight caused by Alternaria solani (11). Other genotypes of $S$. habrochaites were resistant to late blight caused by $P$. infestans $(6,7)$, whitefly infestations (38), whitefly-transmitted Geminivirus spp. (36), and Bemisia argentifolli (38). This wild species can be crossed with S. lycopersicon to generate progeny with relative ease $(6,7,13)$, making the species a good candidate for improving tomato disease resistance.

When screening for economically important traits, breeders have performed host samplings under the assumption that taxonomically related plants, or those found in geographic proximity, are likely to share desirable characteristics such as disease resistance $(22,23,57)$. The third objective of our study was to determine whether resistance to $P$. capsici could be found in diverse tomato lineages or whether it was only associated with one or more particular clades. If a breeder can use taxonomic or geographic information to identify the most likely sources of valuable traits, then the efficiency of the search may be improved (22). To determine the relatedness of the tomato genotypes used in this study, we relied on AFLP analysis. AFLP analysis is an appropriate tool to detect polymorphisms in tomato and establish genetic diversity and relatedness among tomato genotypes (42, 59). The obtained UPGMA tree topology agreed with clustering analysis of previous studies $(1,37,42,59)$ and the statistical analysis found no correlation between UPGMA clade and resistance to the pathogen isolates used in this study, indicating that the tree topology obtained cannot be reliably used to predict where additional sources of $P$. capsici resistance may be found. Resistance to isolate SFF3 seems to be more widespread across tomato lineages than for the other P. capsici isolates used in our experiment. Spooner et al. (58) also found that resistance to $P$. infestans was not associated with lineages of wild potato. Our results suggests that tomato germplasm needs to be screened for resistance to diverse $P$. capsici isolates until other methods, such as marker-assisted selection, are developed to identify resistant genotypes. The association between $P$. capsici resistance and geographic origin of tomato genotypes was not analyzed in this study because the origin of most cultivars is unknown. Information on geographic origin is only available for LA407, that comes from Ecuador; Ha7998, that comes from Hawaii; and LA1269, LA1589, and LA716, that come from Peru. More accessions of the wild species used in this study need to be included in future experiments to establish whether the responses observed occur in other accessions of the same species, and to determine whether the lack of association between resistance to $P$. capsici and AFLP clades is due to the low number of Solanum accessions tested or to genetic effects.

$P$. capsici has been documented in many vegetable production regions in Michigan (18), a state that grows over 33,000 ha of susceptible crops (3). In Michigan, a grower's ability to grow vegetables in uninfested land is diminished due to a general reduction in farmland caused by urban sprawl and an increase in the number of $P$. capsici-infested fields. In addition, fungicide resistance, an increasing list of susceptible hosts, and the phasing out of methyl bromide treatments make cost-effective management of $P$. capsici difficult. Disease management strategies that reduce fungicide use without increasing disease related losses, such as host resistance, are needed.

\section{ACKNOWLEDGMENTS}

We thank all the members of the Hausbeck lab for their valuable suggestions and help; J. Passmore, M. Mercier, A. Lebeis, and M. Wood for technical assistance; D. Francis, T. Aldrich, and S. Smith for providing seed; B. Webster, L. Granke, and S. Linderman for editing; A. Worth for help with pictures; and S. Glaspie and B. Harlan for greenhouse assistance. This material is based upon work supported by the MSU Michigan Agriculture Experiment Station Hatch Project 01966, the United States Department of Agriculture (USDA) Cooperative State Research, Education and Extension Service (CSREES), Specialty Crops Research Initiative Grant under award no. 2008-51180-04881, and the USDA-CSREES Special Research Grant under awards no. 2006-3457216902 and 2008-34572-16902.

\section{LITERATURE CITED}

1. Alvarez, A. E., van de Wiel, C. C. M., Smulders, M. J. M., and Vosman, B. 2001. Use of microsatellites to evaluate genetic diversity and species relationships in the genus Lycopersicon. Theor. Appl. Genet. 103:12831292.

2. Anonymous. 2008. National Statistics: Tomatoes. United States Department of Agriculture, National Agricultural Statistics Service. Online publication.

3. Anonymous. 2009. National Statistics: Michigan Data-Vegetables. United States Department of Agriculture, National Agricultural Statistics Service. Online publication.

4. Bolkan, H. A. 1985. A technique to evaluate tomatoes for resistance to Phytophthora root rot in the greenhouse. Plant Dis. 69:708-709.

5. Bowers, J. H., and Mitchell, D. J. 1989. Variability in virulence of oospore inoculum of Phytophthora capsici and the relationship of the density of oospores in soil to plant mortality. (Abstr.) Phytopathology 79:1166.

6. Brower, D. J., Jones, E. S., and St. Clair, D. 2004. QTL analysis of quantitative resistance to Phytophthora infestans (late blight) in tomato and comparisons with potato. Genome 47:475-492.

7. Brower, D. J., and St. Clair, D. A. 2004. Fine mapping of three quantitative trait loci for late blight resistance in tomato using near isogenic lines (NILs) and sub-NILs. Theor. Appl. Genet. 108:628-638.

8. Critopoulos, P. D. 1955. Foot rot of tomato incited by Phytophthora capsici. Bull. Torrey Bot. Club 82:168-182.

9. Erwin, D. C., and Ribeiro, O. K. 1996. Phytophthora Diseases Worldwide. American Phytopathological Society Press, St. Paul, MN.

10. Eshed, Y., and Zamir, D. 1995. An introgression line population of Lycopersicon pennellii in the cultivated tomato enables the identification and fine mapping of yield-associated QTL. Genetics 141:1147-1162.

11. Foolad, M. R., Ntahimpera, N., Christ, B. J., and Lin, G. Y. 2000. Comparison of field, greenhouse, and detached-leaflet evaluations of tomato germ plasm for early blight resistance. Plant Dis. 84:967-972.

12. Foster, J. M., and Hausbeck, M. K. 2010. Resistance of pepper to Phytophthora crown, root, and fruit rot is affected by isolate virulence. Plant Dis. 94:24-30.

13. Francis, D. M., Kabelka, E., Bell, J., Franchino, B., and St. Clair, D. 2001 Resistance to bacterial canker in tomato (Lycopersicon hirsutum LA407) and its progeny derived from crosses to $L$. esculentum. Plant Dis. 85:1171-1176.

14. Gevens, A. J., Ando, K., Lamour, K. H., Grumet, R., and Hausbeck, M. K. 2006. A detached cucumber fruit method to screen for resistance to Phytophthora capsici and effect of fruit age on susceptibility to infection. Plant Dis. 90:1276-1282.

15. Gevens, A. J., and Hausbeck, M. K. 2004. Phytophthora capsici isolated from snap beans is pathogenic to cucumber fruit and soybean. (Abstr.) Phytopathology 95:S162.

16. Gullino, M. L., and Garibaldi, A. 1994. Influence of soilless cultivation on soilborne diseases. Acta Hortic. 361:341-354.

17. Hartman, H., and Huang, Y. H. 1993. Pathogenicity and virulence of 
Phytophthora capsici isolates from Taiwan on tomatoes and other selected hosts. Plant Dis. 77:588-591.

18. Hausbeck, M. K., and Lamour, K. H. 2004. Phytophthora capsici on vegetable crops: Research progress and management challenges. Plant Dis. 88:1292-1303.

19. Hwang, B. K., Kim, Y. J., and Kim, C. H. 1996. Differential interactions of Phytophthora capsici isolates with pepper genotypes at various growth stages. Eur. J. Plant Pathol. 102:311-316.

20. Hwang, J. S., and Hwang, B. K. 1993. Quantitative evaluation of resistance of Korean tomato cultivars to isolates of Phytophthora capsici from different geographic areas. Plant Dis. 77:1256-1259.

21. Ioannou, N., and Grogan, R. G. 1984. Control of Phytophthora root rot of processing tomato with ethazol and metalaxyl. Plant Dis. 68:429-435.

22. Jansky, S. H., Simon, R., and Spooner, D. M. 2006. A test of taxonomic predictivity: Resistance to white mold in wild relatives of cultivated potato. Crop Sci. 46:2561-2570.

23. Jansky, S. H., Simon, R., and Spooner, D. M. 2008. A test of taxonomic predictivity: Resistance to early blight in wild relatives of cultivated potato. Phytopathology 98:680-687.

24. Jones, J. B. 1999. Tomato Plant Culture in the Field, Greenhouse and Home Garden. CRC Press LLC, Boca Raton, FL.

25. Kabelka, E., Franchino, B., and Francis, D. M. 2002. Two loci from Lycopersicon hirsutum LA407 confer resistance to strains of Clavibacter michiganensis subsp. michiganensis. Phytopathology 92:504-510.

26. Kim, E. S., and Hwang, B. K. 1992. Virulence to Korean pepper cultivars of isolates of Phytophthora capsici from different geographic areas. Plant Dis. 76:486-489.

27. Kim, K., Nemec, S., and Musson, G. 1997. Effects of compost and soil amendments on soil microflora and Phytophthora root and crown rot of bell pepper. Crop Prot. 16:165-172.

28. Kreutzer, W. A., Bodine, E. W., and Durrell, L. W. 1940. Cucurbit diseases and rot of tomato fruit caused by Phytophthora capsici. Phytopathology 30:972-976.

29. Labuschagne, N., Thompson, A. H., and Botha, W. J. 2003. First report of stem and root rot of tomato caused by Phytophthora capsici in South Africa. Plant Dis. 87:1540.

30. Lamour, K. H., and Hausbeck, M. K. 2000. Mefenoxam insensitivity and the sexual stage of Phytophthora capsici in Michigan cucurbit fields. Phytopathology 90:396-400.

31. Lamour, K. H., and Hausbeck, M. K. 2001. The dynamics of mefenoxam insensitivity in a recombining population of Phytophthora capsici characterized with amplified fragment length polymorphism markers. Phytopathology 91:553-557.

32. Lamour, K. H., and Hausbeck, M. K. 2003. Effect of crop rotation on the survival of Phytophthora capsici in Michigan. Plant Dis. 87:841-845.

33. Lamour, K. H., and Hausbeck, M. K. 2003. Susceptibility of mefenoxamtreated cucurbits to isolates of Phytophthora capsici sensitive and insensitive to mefenoxam. Plant Dis. 87:920-922.

34. Lee, B. K., Kim, B. S., Chang, S. W., and Hwang, B. K. 2001. Agressiveness to pumpkin cultivars of isolates of Phytopththora capsici from pumpkin and pepper. Plant Dis. 85:497-500.

35. Maniatis, T., Fritsch, E. F., and Sambrook, J. 1982. Molecular Cloning: A Laboratory Manual. Cold Spring Harbor Laboratory, Cold Spring Harbor, NY.

36. Martins Santana, F., da Graça Ribeiro, S., Willians Moita, A., Moreira, D., and de Brito Giordano, L. 2001. Sources of resistance in Lycopersicon spp. to a bipartite whitefly-transmitted geminivirus from Brazil. Euphytica 122:45-51.

37. Miller, J. D., and Tanksley, S. D. 1990. RFLP analysis of phylogenetic relationships and genetic variation in the genus Lycopersicon. Theor. Appl. Genet. 80:437-448.

38. Muigai, S. G., Schuster, D. J., Snyder, J. C., Scott, J. W., Bassett, M. J., and McAuslane, H. J. 2002. Mechanisms of resistance in Lycopersicon germplasm to the whitefly Bemisia argentifolii. Phytoparasitica 30:347360.

39. Noble, R., and Coventry, E. 2005. Suppression of soil-borne plant diseases with composts: A review. Biocontrol Sci. Technol. 15:3-20.

40. Oelke, L. M., and Bosland, P. W. 2003. Differentiation of race specific resistance to Phytophthora root rot and foliar blight in Capsicum annuum. J. Am. Soc. Hortic. Sci. 128:213-218.

41. Palloix, A., Daubeze, A. M., and Pochard, E. 1988. Phytophthora root rot of pepper. Influence of host genotype and pathogen strain on the inoculum-density severity relationships. J. Phytopathol. 123:25-33.

42. Park, Y. H., West, M. A. L., and St. Clair, D. A. 2004. Evaluation of AFLPs for germplasm fingerprinting and assessment of genetic diversity in cultivars of tomato (Lycopersicon esculentum L.). Genome 47:510-518.

43. Parra, G., and Ristaino, J. B. 2001. Resistance to mefenoxam and metalaxyl among field isolates of Phytopththora capsici causing Phytophthora blight of bell pepper. Plant Dis. 85:1069-1075.

44. Polach, F. J., and Webster, R. K. 1972. Identification of strains and inheritance of pathogenicity in Phytophthora capsici. Phytopathology 62:20-26.

45. Quesada-Ocampo, L. M., Fulbright, D. W., and Hausbeck, M. K. 2009. Susceptibility of Fraser fir to Phytophthora capsici. Plant Dis. 93:135141.

46. Quesada-Ocampo, L. M., and Hausbeck, M. K. 2009. Resistance in tomato and wild relatives to Phytophthora capsici. (Abstr.) Phytopathology 99:S106.

47. Quirin, E. A., Ogundiwin, E. A., Prince, J. P., Mazourek, M., Briggs, M. O., Chlanda, T. S., Kim, K.-T., Falise, M., Kang, B.-C., and Jahn, M. M. 2005. Development of sequence characterized amplified region (SCAR) primers for the detection of Phyto.5.2, a major QTL for resistance to Phytophthora capsici Leon. in pepper. Theor. Appl. Genet. 110:605-612.

48. Reifschneider, F. J. B., Adalberto, C. C. F., and Arildo, M. R. 1986 Factors affecting expression of resistance in pepper (Capsicum annuum) to blight caused by Phytophthora capsici in screening trials. Plant Pathol. 35:451-456.

49. Rick, C. M., and Yoder, J. I. 1988. Classical and molecular genetics of tomato: Highlights and perspectives. Annu. Rev. Genet. 22:281-300.

50. Ristaino, J. B. 1990. Intraspecific variation among isolates of Phytopthora capsici from pepper and cucurbit fields in North Carolina. Phytopathology 80:1253-1259.

51. Ristaino, J. B., Madritch, M., Trout, C. L., and Parra, G. 1998. PCR amplification of ribosomal DNA for species identification in the plant pathogen genus Phytophthora. Appl. Environ. Microbiol. 64:948-954.

52. Roberts, P. D., French-Monar, R. D., Hoffine, M. S., Seijo, T. E., and McGovern, R. J. 2005. Survival and recovery of Phytophthora capsici and oomycetes in tailwater and soil from vegetable fields in Florida. Ann. Appl. Biol. 146:351-359.

53. Sacristan, S., and Garcia-Arenal, F. 2008. The evolution of virulence and pathogenicity in plant pathogen populations. Mol. Plant Pathol. 9:369. 384.

54. Satour, M. M., and Butler, E. E. 1967. A root and crown rot of tomato caused by Phytophthora capsici and P. parasitica. Phytopathology 57:510-515.

55. Saude, C., Hurtado-Gonzalez, O. P., Lamour, K. H., and Hausbeck, M. K. 2008. Occurrence and characterization of a Phytophthora sp. pathogenic to asparagus (Asparagus officinalis) in Michigan. Phytopathology 98:1075-1083.

56. Shaner, G., and Finney, R. E. 1977. The effect of nitrogen fertilization on the expression of slow-mildewing resistance in Knox wheat. Phytopathology 67:1051-1056.

57. Spooner, D. M., Hetterscheid, W. L. A., van den Berg, R. G., and Brandenburg, W. 2003. Plant nomenclature and taxonomy: A horticultural and agronomic perspective. Hortic. Rev. (Am. Soc. Hortic. Sci.) 28:1-60.

58. Spooner, D. M., Jensky, S. H., and Simon, R. 2009. Test of taxonomic and biogeographic predictivity: Resistance to disease and insect pests in wild relatives of cultivated potato. Crop Sci. 49:1367-1376.

59. Spooner, D. M., Peralta, I. E., and Knapp, S. 2005. Comparison of AFLPs with other markers for phylogenetic inference in wild tomatoes [Solanum L. section Lycopersicon (Mill.) Wettst.]. Taxon 54:43-61.

60. Swofford, D. L. 1996. PAUP*: Phylogenetic Analysis Using Parsimony (and Other Methods), 4.0. Sinauer Associates, Sunderland, MA.

61. Sy, O., Bosland, P. W., and Steiner, R. 2005. Inheritance of Phytophthora stem blight resistance as compared to Phytophthora root rot and Phytophtora foliar blight in Capsicum annuum L. J. Am. Soc. Hortic. Sci. 130:75-78

62. Sy, O., Steiner, R., and Bosland, P. W. 2008. Recombinant inbred line differential identifies race-specific resistance to Phytophthora root rot in Capsicum annuum. Phytopathology 98:867-870.

63. Walker, S. J., and Bosland, P. W. 1999. Inheritance of Phytopthora root rot and foliar blight resistance in pepper. J. Am. Soc. Hortic. Sci. 124:14-18.

64. Waterhouse, G. M. 1963. Key to the Species of Phytophthora de Bary. Commonwealth Mycological Society, Kew, Surrey, UK. 